\title{
Nitrogen Oxides Concentration and Emission Change Detection During COVID-19 Restrictions in North India
}

\section{Prakhar Misra ( $\nabla$ mprakhar@chikyu.ac.jp )}

Research Institute for Humanity and Nature, Kyoto

Masayuki Takigawa

Japan Agency for Marine-Earth Science and Technology, Yokohama

Pradeep Khatri

Graduate School of Science, Tohoku University, Sendai

\section{Surendra Dhaka}

Radio and Atmospheric Physics Lab, Rajdhani College, University of Delhi

\section{A. Dimri}

School of Environmental Sciences, Jawaharlal Nehru University, Delhi

\section{Kazuyo Yamaji}

Kobe University, Kobe

\section{Mizuo Kajino}

Meteorological Research Institute, Japan Meteorological Agency, Tsukuba

\section{Wataru Takeuchi}

Institute of Industrial Science, The University of Tokyo, Tokyo

Ryoichi Imasu

Atmosphere and Ocean Research Institute, The University of Tokyo, Chiba

Prabir Patra

Japan Agency for Marine-Earth Science and Technology, Yokohama

Sachiko Hayashida

Research Institute for Humanity and Nature, Kyoto

\section{Research Article}

Keywords: NOx, lockdown, top-down emission, TROPOMI, Emission inventory, power plant

Posted Date: December 8th, 2020

DOI: https://doi.org/10.21203/rs.3.rs-116325/v1 
License: (c) (i) This work is licensed under a Creative Commons Attribution 4.0 International License. Read Full License 


\title{
Nitrogen Oxides Concentration and Emission change detection during COVID-19 restrictions in North India
}

\author{
Prakhar Misra $^{1 *}$, Masayuki Takigawa ${ }^{2}$, Pradeep Khatri ${ }^{3}$, S.K. Dhaka ${ }^{4}$, A.P. Dimri ${ }^{5}$, Kazuyo Yamaji ${ }^{6}$, \\ Mizuo Kajino ${ }^{7}$, Wataru Takeuchi' ${ }^{8}$, Ryoichi Imasu' ${ }^{9}$, Prabir K. Patra ${ }^{2}$, Sachiko Hayashida1,10 \\ ${ }^{1}$ Research Institute for Humanity and Nature, Kyoto, Japan; mprakhar@chikyu.ac.jp \\ ${ }^{2}$ Japan Agency for Marine-Earth Science and Technology, Yokohama, Japan \\ ${ }^{3}$ Graduate School of Science, Tohoku University, Sendai, Japan \\ ${ }^{4}$ Radio and Atmospheric Physics Lab, Rajdhani College, University of Delhi, New Delhi, India \\ ${ }^{5}$ School of Environmental Sciences, Jawaharlal Nehru University, New Delhi, India \\ ${ }^{6}$ Kobe University, Kobe, Japan \\ ${ }^{7}$ Meteorological Research Institute, Japan Meteorological Agency, Tsukuba, Japan \\ ${ }^{8}$ Institute of Industrial Science, The University of Tokyo, Tokyo, Japan \\ ${ }_{9}^{9}$ Atmosphere and Ocean Research Institute, The University of Tokyo, Chiba, Japan \\ ${ }^{10}$ Faculty of Science, Nara Women's University, Nara, Japan \\ * Correspondence: mprakhar@chikyu.ac.jp; Tel.: (+81 70-4813-2297)
}

\begin{abstract}
COVID-19 induced restrictions resulted in a lowered fine aerosol particle and trace gas concentration across several urban places around the world, providing a natural opportunity to study effects of anthropogenic activities on emissions of air pollutants. Impact of sudden suspension of human activities on air pollution was analyzed by studying the change in satellite retrieved $\mathrm{NO}_{2}$ concentrations and top-down NOx emission over the urban and rural areas around Delhi. $\mathrm{NO}_{2}$ was chosen for being the most indicative of emission intensity due to its short lifetime of the order of a few hours in the planetary boundary layer. We present a robust temporal comparison of Ozone Monitoring Instrument (OMI) retrieved $\mathrm{NO}_{2}$ column density during the lockdown with the counterfactual baseline concentrations, extrapolated from the long-term trend and seasonal cycle components of $\mathrm{NO}_{2}$ using observations during 2015 to 2019. $\mathrm{NO}_{2}$ columns in the urban area of Delhi experienced an anomalous relative change ranging from $60.0 \%$ decline during the Phase 1 of lockdown (March 25-April 13, 2020) to 3.4\% during the post-lockdown Phase 5. In contrast, we find no substantial reduction in $\mathrm{NO}_{2}$ concentrations over the rural areas. To clarify the quantitative impact of the lockdown measures, weekly top-down NOx emissions were estimated from TROPOspheric Monitoring Instrument (TROPOMI) retrieved $\mathrm{NO}_{2}$ by accounting for horizontal advection derived from the steady state continuity equation. NOx emissions from urban areas and power plants exhibited a mean decline of $72.19 \%$ and $53.4 \%$ respectively in Phase 1 compared to the pre-lockdown business-as-usual phase. Due to absence of confounding emission source activity during lockdown, emission estimates over urban areas and power-plants were validated with respective electricity generation reports and Google's mobility reports. A higher anomaly in emission estimates suggests that comparison of only concentration change, without accounting for the dynamical and photochemical conditions, may mislead evaluation of lockdown impact. Our results are also useful for optimizing bottom-up emission inventories.
\end{abstract}

Keywords: NOx, lockdown; top-down emission; TROPOMI; Emission inventory; power plant 


\section{Introduction}

Movement restrictions or lockdowns have emerged as the most popular social policy to prevent COVID-19 transmission. This policy has induced natural experiment on a global scale with spillover social $^{1}$, economic ${ }^{1,2}$ and environmental impacts ${ }^{3-5}$. For environmental impacts, natural experiments like volcanic eruptions and unintended anthropogenic modifications like ship tracks have been utilized for constraining unknowns in understanding the role of meteorological conditions, emissions and atmospheric chemistry on air pollutant concentrations ${ }^{4,6}$.

Early lockdown in January and February in China resulted in decreased economic activities, revealing a decline in regional pollutants, specially the nitrogen oxides $\left(\mathrm{NOx} \equiv \mathrm{NO}+\mathrm{NO}_{2}\right)$. $\mathrm{NOx}$ forms a key short-lived (2-7 hours) tropospheric air pollutant in urban areas that is produced primarily from fossil fuel combustion. Primary emission mostly takes place in the form of NO which then gets oxidized through chemical and photolytic pathways to $\mathrm{NO}_{2}$, collectively referred to as $\mathrm{NOx}$. Investigating NOx concentrations gained an additional importance during COVID-19 related lockdowns because it allowed clear estimation of the impact of local policy actions as it is less prone to long-range transport owing to its short life-time. $\mathrm{NO}_{2}$ concentrations in Chinese cities decreased by up to $50 \%$ to $60 \%$ as measured by ground monitors 7,8 , and Ozone Monitoring Instrument (OMI) and TROPOspheric Monitoring Instrument (TROPOMI) satellite retrieved columns ${ }^{4,6}$. Strong declines in $\mathrm{NO}_{2}$ were also observed in Europe, South Korea, and the United States ${ }^{5,9}$. Investigating sources of NOx is important due to their direct and indirect health impacts ${ }^{10}$. Indian cities went under varying intensities of 'lockdown' severity since March 25, 2020. About $60 \%$ to $90 \%$ decline in surface NOx concentrations was observed at a road-site in Delhi during the first week of lockdown compared to the pre-lockdown week ${ }^{11,12}$. Similar large reductions were seen across other large cities in Northern India ${ }^{13,14}$. A review of change in pollutant concentration across Indian cities as measured by ground monitors is summarized elsewhere ${ }^{13,15}$.

However, short-term NOx concentrations are regulated not only through the emissions but also non-linearly through meteorology and atmospheric chemistry. Therefore, it remains hard to conclude how much reductions can be attributed to the lockdown restrictions $s^{4,9,13,16}$. $\mathrm{NO}_{2}$ concentrations have an inverse linear relationship with boundary layer height and wind speed within the boundary layer due to upliftment of air mass ${ }^{17}$. These meteorological effects are manifested through seasonality of NOx concentrations. Long-term trends and seasonality in NOx concentrations have been extensively studied over India using ground monitoring stations and satellite retrieved datasets ${ }^{18,19}$. These trends are associated with rapid economic growth translating to rapid urbanization, increased vehicle population and density, increase in industries and industrial output. At the same time policies measures have also been directed to reduce emissions by implementing stricter emission norms for vehicles and industries.

We hypothesize that considering such seasonality and long-term changes, lockdown impacts towards changing the NOx concentrations can be ascertained by assessing both the change in concentration as well as emissions. So far, a handful of studies have systematically discussed the impact of lockdown on NOx emissions by considering the effect of wind fields on pollutant transport ${ }^{20-22}$, for example by simulating wind trajectories using for example, NOAA's HYSPLIT model. To assess the impact of lockdown in northern India, we adopt a novel methodology to estimate the impact of lockdown on emissions, whereby top-down emissions were calculated by incorporating spatial changes in $\mathrm{NO}_{2}$ flux due to wind vector fields. We assessed weekly trends in concentration in the context of 2015-2020 satellite records as well as top-down NOx emissions. We perform this by spatially analyzing satellite retrieved $\mathrm{NO}_{2}$ datasets. Our work thus contributes to untangling the emission change from concentration change.

The objective of this research is to use a time-series of satellite retrieved $\mathrm{NO}_{2}$ columns to investigate the temporal and spatial impact of COVID-19 induced restriction measures on $\mathrm{NO}_{2}$ concentration and NOx emission over a polluted region in Indo-Gangetic Plains (shown in Figure 1). Our novelty lies in quantifying the impact of lockdown robustly through satellite derived top-down NOx emissions which were calculated by applying a steady state continuity model to $\mathrm{NO}_{2}$ column imagery. Estimating the impact of reduced human activities on nitrogen oxide emissions and its 
concentrations can help in constraining the emission inventories and segregating the contribution of the regional emission sources.

\section{Methodology}

The analysis flowchart of the study is summarized in Figure S1.

\subsection{Study Location and policy restrictions}

The study domain is defined over a region $\left(74^{\circ} \mathrm{E}, 27^{\circ} \mathrm{N}-80^{\circ} \mathrm{E}, 30^{\circ} \mathrm{N}\right)$ in the Indo-Gangetic Plains (IGP) as shown in Figure 1. The domain is notable for its high air pollution, dense settlements and polluting industries. It includes diverse area and point emission sources such as densely populated urban Delhi (urban center: $77.21^{\circ} \mathrm{E}, 28.60^{\circ} \mathrm{N}$ ), smaller cities such as Meerut (urban center: $77.70^{\circ} \mathrm{E}, 28.98^{\circ} \mathrm{N}$ ), Mathura (urban center: $77.67^{\circ} \mathrm{E}, 27.49^{\circ} \mathrm{N}$ ), Aligarh (urban center: $78.07^{\circ} \mathrm{E}, 27.87^{\circ} \mathrm{N}$ ), strongly emitting power-plants at Dadri (location: $77.61^{\circ} \mathrm{E}, 28.60^{\circ} \mathrm{N}$; capacity: $2600 \mathrm{MW}$ ), Harduaganj (location: $78.13^{\circ} \mathrm{E}$, $28.01^{\circ} \mathrm{N}$; capacity $610 \mathrm{MW}$ ) and Jhajjar (location: $76.35^{\circ} \mathrm{E}, 28.49^{\circ} \mathrm{N}$; capacity: $1320 \mathrm{MW}$ ), an expressway network radiating outward from the center, as well as rural background regions not lying downwind of emission sources (sample region bounded by $75.38^{\circ} \mathrm{E}, 29.38^{\circ} \mathrm{N}-75.13 \mathrm{vE}, 29.90^{\circ} \mathrm{N}$ ). In the domain, climatic conditions vary from a mean low temperature of $3^{\circ} \mathrm{C}$ during winter (December to February) to a high of $45^{\circ} \mathrm{C}$ during the pre-monsoon summer (March - June).

In India business-as-usual (BAU) prevailed prior to March 22, 2020 as there was no movement restriction pertaining to COVID-19. The lockdown was implemented over India in several phases starting from March 25 (week 13) and lasting till May 31. Phase 1 of the lockdown consisted of the strictest restrictions followed by relaxation of restriction intensities in subsequent phases. From June 1, 2020 the lockdown was gradually rolled back (Phase 5). The timeline of the lockdown phases with regards to restrictions on the common emission sources is shown in Table S1.
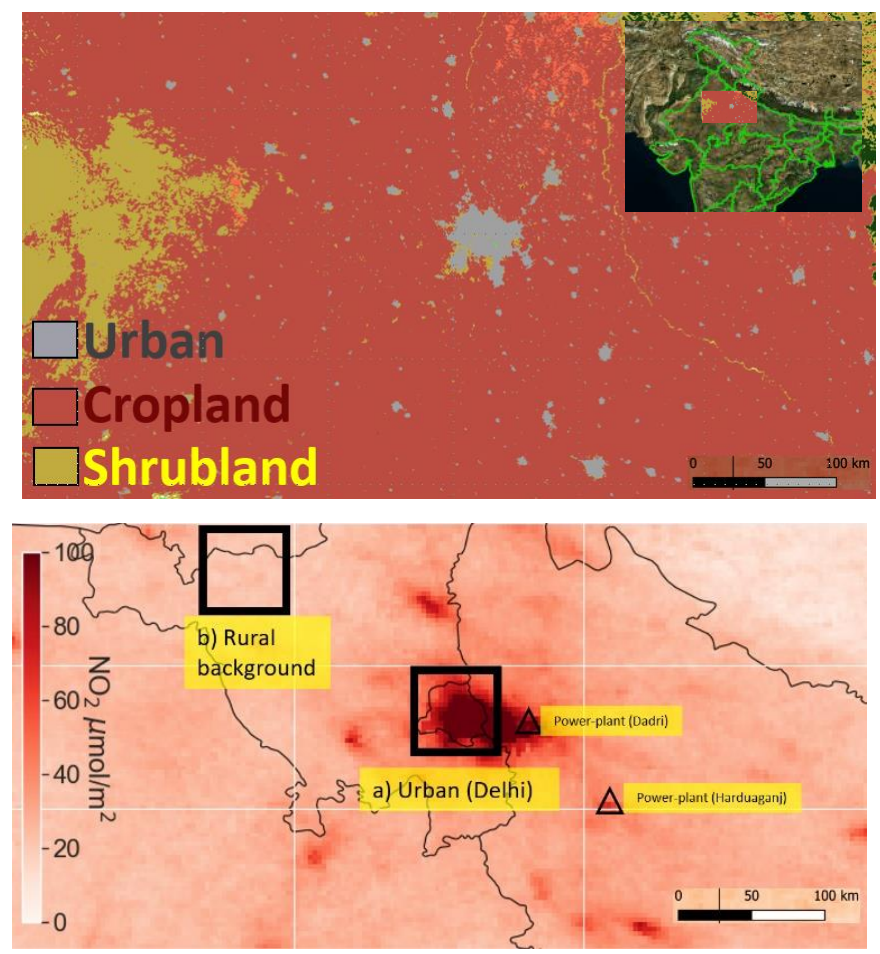

Figure 1. (top) Dominant land cover types in the study domain $\left(74^{\circ} \mathrm{E}, 27^{\circ} \mathrm{N}-80^{\circ} \mathrm{E}, 30^{\circ} \mathrm{N}\right)$ are urban areas, croplands and desert shrublands. (bottom) Mean NO2 column density (TROPOMI) in the week before the enactment of Phase 1 of lockdown March 16-20 (week 12), 2020. Location of representative 
urban area (Delhi) and rural background (Fatehabad) are shown in box, in addition to other prominent neighboring emission sources (power-plant at Dadri and Harduaganj).

\subsection{Datasets}

\subsubsection{OMI (2015-2020) and TROPOMI (2019-2020) retrieved tropospheric $\mathrm{NO}_{2}$ column}

Tropospheric $\mathrm{NO}_{2}$ column retrievals were obtained from the OMI on-board Aura satellite ${ }^{23}$ and the TROPOMI on-board Copernicus Sentinel-5 Precursor satellite ${ }^{24}$. $\mathrm{NO}_{2}$ from OMI (henceforth referred to as $\mathrm{OMI} \mathrm{NO}$ ) is available since 2004 at a pixel size of approximately $13 \times 24 \mathrm{~km}^{2}$. While offline and near-real time $\mathrm{NO}_{2}$ from TROPOMI (henceforth referred to as TROPOMI $\mathrm{NO}_{2}$ ) has become available only recently (since mid-2018) but at a higher spatial resolution of $6 \times 7 \mathrm{~km}^{2}$. OMI $\mathrm{NO}_{2}$ 's 30\% cloud-screened daily level 3 product was downloaded from NASA's Giovanni portal ${ }^{25}$. Level 3 TROPOMI $\mathrm{NO}_{2}$ product was cloud screened (by considering pixels with effective cloud fraction less than 20\%) and analyzed at Google Earth Engine cloud platform ${ }^{26}$. Both $\mathrm{OMI} \mathrm{NO}_{2}$ and TROPOMI $\mathrm{NO}_{2}$ follow a similar $\mathrm{NO}_{2}$ column retrieval algorithm. First slant columnar densities (SCD) are retrieved by differential optical absorption spectroscopy (DOAS) fitting of the backscattered radiance to lab-measured absorption spectra of atmospheric gases such as $\mathrm{NO}_{2}, \mathrm{O} 3$, water vapor and others. From the SCD, tropospheric vertical column densities (VCD) are isolated by removing the stratospheric contribution and applying air mass fractions ${ }^{27}$. Typically, OMI and TROPOMI retrieve $\mathrm{NO}_{2}$ at approximately 13:30 hours (local time). Aggregation of the daily concentration (from Monday to Sunday) in each week to their weekly mean concentration was done to overcome the periodic weekly cycle of increase (on weekdays) and decrease (on weekends) in $\mathrm{NO}_{2}$ concentrations ${ }^{32}$

\subsubsection{Reanalysis meteorological data}

Wind field vectors $(w)$ at 80 meter altitude were used for estimating $\mathrm{NO}_{2}$ flux. The meteorological fields were obtained from National Center for Environmental Prediction (NCEP) FNL (Final) Operational Global Analysis and Forecast gridded datasets ${ }^{28}$ and are available at $0.25^{\circ} \times 0.25^{\circ}$ spatial resolution every 6 hours. To ensure compatibility with satellite datasets, analysis was performed with forecasts for 13:30 hours (local time). The time series of meteorological parameters over Delhi is shown in Figure S2.

\subsubsection{Activity data}

Although updated or real-time emission estimation is seldom available in most countries, human activity in the form of energy production and travel behavior change reports serve as reliable proxies for changes in emission activities ${ }^{29}$. We used daily total electricity production tables available for each power-plant, from the Power System Operation Corporation Limited ${ }^{30}$ to infer the emission from coal-based thermal power plants situated around Delhi, Harduaganj and Dadri. Since February 2020, percentage reduction in daily mobility patterns from the baseline levels, aggregated for administrative state are available from Google's Community Mobility Reports (Google n.d.). The reports show the movement trends by region, across different categories of places. The defined baseline period represents median value from the 5-week period January 3 to February 6, 2020. Out of the available patterns 'workplace related travel' behavior reduction was used based on the assumption it represents the most common vehicle usage in the study domain.

\subsection{Concentration change estimation}

$\mathrm{NO}_{2}$ concentrations over Indian cities in Indo Gangetic Plain (IGP) are known to exhibit annual seasonality and long term trends ${ }^{18}$. The seasonality can be explained by the seasonal variation in emission activity and source strengths, $\mathrm{NO}_{2}$ lifetimes due to chemistry of hydroxyl radical $(\mathrm{OH})$ and photolysis under changing solar zenith angle, and meteorological effects like dispersal, wet and dry deposition processes. Whereas long term trends are in response due to gradual changes in 
anthropogenic emissions from industries and vehicles owing to technological, economical and policy related changes.

Owing to the limited temporal record of TROPOMI NO 2 , it was used only for comparing the spatial changes in NO2 column densities between 2019 and 2020. Mean NO2 concentrations of 2019 for corresponding weeks of the year in 2020 were used as reference concentrations for TROPOMI's spatial anomaly calculation. Although data from just one year is insufficient to represent the weekly baseline concentrations, it still can account for broader seasonality caused due to the changing solar zenith angle to reveal spatial patterns in $\mathrm{NO}_{2}$ anomaly.

The OMI $\mathrm{NO}_{2}$ with its coarser spatial resolution but longer temporal record, was used for obtaining the expected baseline concentration in 2020, $C_{B}$ if business-as-usual conditions had continued. $C_{B}(t)$ was extrapolated from the low frequency annual trends and high frequency seasonal cycle decomposed from the mean weekly satellite retrieved NO2 columns $C_{o}$ during 2015 to 2019. The decomposition was performed using the 'seasonal and trend decomposition' (STL), while extrapolation was performed by exponential trend smoothing (ETS) functions available in R language. To ensure that STL decomposition was not affected by outlying pollution episodes, concentrations higher than 99.5 percentiles were discarded. Box-cox transformation was performed on the concentration prior to STL decomposition to ensure they are normally distributed. Pollution episodes that are non-periodic or random interventions could not be decomposed statistically and were identified as residues. ETS extrapolation was repeated using bootstrap sampling with 1000 draws to obtain the confidence interval of the predictions. Due to computation requirements for STL decomposition and the ETS extrapolation, expected $C_{B}$ were calculated only over urban Delhi and the background rural region (location bounds are as specified in the previous Section).

\subsection{Top-down emission change retrieval}

Several methods exist for deriving NOx emissions using satellite retrieved columns: optimizing the priori available emission inventories with satellite derived top-down constraints on NOx emissions ${ }^{33}$, inversely fitting the dispersion model on the concentrations over the affected region to derive emissions from the source region ${ }^{34,35}$ or applying mass conservation based continuity equation ${ }^{36}$. Constraining emission inventories present a compromise between the high spatial resolution of TROPOMI and the coarser model simulation, especially close to strong emission sources ${ }^{34}$. Dispersion models require a careful definition of the region affected by plume advection, by choosing the product of wind-speed and the NOx lifetime ${ }^{34}$. Emissions thus calculated are underestimated if the region is not large enough to contain most of the emitted NOx, or overestimated should the NOx be influenced by other strong sources outside or inside the region ${ }^{34}$. In practice such conditions are hard to meet over linear or area-based emission sources. As seen in the mean $\mathrm{NO}_{2}$ column in Figure 1, advected plumes overlap with downwind emission sources.

With such challenges, continuity equation models are better placed to estimate emissions from multiple point-sources if wind vectors are adequately available. They are based on the energy conservation and mass balance for a fluid in steady state at each location. Furthermore, such models do not require defining a region around each emission plume and allow emission estimation over each pixel unlike dispersion models. Our approach is inspired from Beirle et al., ${ }^{36}$, in which using a continuity equation the divergence $(D)$ of NOx emission flux can be related with the sink $(S)$ and the emission $(E)$ as $D=E+S$. The daytime NOx sink is constituted by reaction of $\mathrm{NO}_{2}$ with $\mathrm{OH}$ to form $\mathrm{HNO}_{3}{ }^{37}$. The total emission flux along meridional and zonal wind fields, $w$, is given as $L C w$, where $C$ is the daily TROPOMI $\mathrm{NO}_{2}$ column, and $L$ is the ratio of $\mathrm{NOx}$ and $\mathrm{NO}_{2}$. Assuming a first order reaction of $\mathrm{NO}_{2}$ with a time constant $\tau, S$ is given as $L C / \tau$. E from using the mass balance is shown in Equation 1.

$$
E=\frac{L C}{\tau}+\nabla(L C w)
$$

$\tau$ corresponds to the average lifetime of NOx in the boundary layer, depending on factors like the photolysis rate, length of night, $\mathrm{OH}$ concentrations and meteorological conditions such as wind, 
relative humidity and temperature ${ }^{32}$. It is of the order of one day but varies by about one order of magnitude with time and place. In tropical regions $\tau$ varies from 7 hours in January to about 4 hours in July ${ }^{33}$. Since the domain lies in a subtropical and semi-arid region, $\tau$ was regressed linearly between 7 to 4 hours depending on the day of the year. $L$ accounts for the partitioning of NOx into $\mathrm{NO}$ and $\mathrm{NO}_{2}$ in the polluted layer by serving as a surrogate for $\mathrm{NO}$ to $\mathrm{NO}_{2}$ chemistry ${ }^{38}$. It depends on ozone concentration, $\mathrm{NO}_{2}$ photolysis rate and temperature. Close to the surface, NOx is present as $\mathrm{NO}_{2}$ except when close to strongly emitting sources where conversion of $\mathrm{NO}$ to $\mathrm{NO}_{2}$ is limited by ozone concentration. A typical value of $L$ as 1.32 was assumed for the urban noon-time pollution conditions ${ }^{36,37}$.

Theoretically the divergence term, $D(=\nabla(L C w))$ should be positive over emission sources and negative elsewhere due to the chemical sink. Following Equation 3, an adequately specified chemical loss sink $S(=L C / \tau)$ numerically compensates the negative $D$ to result in a net zero emission rate $E$ over non-emission source field. However, if the $S$ is underestimated such as by assuming $\tau$ larger than actual lifetime, we would incorrectly obtain negative $E$.

Daily meridional and zonal fluxes were stacked and mean averaged for each week. Pixels masked with cloud masks were not considered. The sum of divergence of mean weekly flux and the sink of mean weekly $\mathrm{NO}_{2}$ column was used to estimate weekly emission rate over each TROPOMI pixel. As the $\tau$ of 4 hours was derived for pollution on top of the tropospheric background concentrations ${ }^{39}$, the sink term $S$ would be biased high in absence of the background correction. A background correction was applied for the $\mathrm{NO}_{2}$ columns by removing the $5^{\text {th }}$ percentile of all columns in the domain ${ }^{36}$.

Emission rates over urban Delhi and power-plants at Dadri and Harduaganj were estimated for comparison with activity reports. A region of spanning $50 \times 50 \mathrm{~km} 2(16 \times 16 \mathrm{TROPOMI}$ pixels $)$ around urban Delhi, and $20 \times 20 \mathrm{~km}^{2}(6 \times 6$ TROPOMI pixels) regions around Dadri and Harduaganj powerplants were selected. The region for calculating emission rate was chosen to avoid overlapping influence from any other strong source. As the continuity model performs mass balance for each pixel, while selecting the region no special consideration was taken regarding the distance to which the plume was advected. Since the region around the power-plants is devoid of other emission sources, background emissions were assumed to be not more than 5 percentiles of the region's emission.

\subsection{Anomaly metric}

An anomaly metric, $\Delta C_{t}$, for a week $t$, was defined as per Equation 2, to quantify the relative change between the mean weekly concentrations (or emissions) in 2020, $C_{2020, t}$, and the corresponding mean reference values, $C_{\text {reference }}$.

$$
\text { anomaly }=\frac{C_{2020, t}-C_{\text {reference }, t}}{C_{\text {reference } t}}
$$

A high absolute anomaly implies a large deviation in $C_{2020}$ with respect to the reference $C_{\text {reference }}$ in the week $t$. Estimating anomaly as per the Equation 2 also offers the benefit of removing systematic additive or multiplicative biases in satellite retrievals. Anomalies in OMI NO2 concentration in 2020 were calculated with respect to extrapolated concentration $C_{B}$ (defined in Section 2.3) as reference. Anomalies in top-down NOx emissions in 2020 were calculated both with emission in 2019 as reference as well as with mean BAU emission as reference. During the lockdown weeks, anomaly was expected to be negative with large absolute values.

\section{Results and discussion}

\subsection{Concentration change during lockdown}

The comparison of the $\mathrm{NO}_{2}$ column in 2020 with that in 2019 suggests a sharp decline in $\mathrm{NO}_{2}$ densities in urban areas with Phase 1 and a subsequent slow recovery. Mean anomaly of TROPOMI $\mathrm{NO}_{2}$ column in 2020 with respect to 2019 for each lockdown phase is shown in Figure S3. Anomaly during BAU was $0.01 \%( \pm 11.0 \%)$, reflecting that prior to lockdown overall densities were not 
different from the baseline, except at Rajiv Gandhi power-plant that showed a high positive anomaly (37.4\%). During Phase 1 lockdown, overall densities had decreased substantially with a large negative mean anomaly $(-33.7 \% \pm 12.1 \%)$, going as low as $-76.8 \%$ over central urban Delhi. Apart from urban areas relatively large negative anomalies were also found above power-plants and industries suggesting reduced emissions compared to 2019. During Phase 2, overall anomaly was reduced to $2.1 \% \pm 17.6 \%$ on account of a sharp difference in anomaly between the rural western region $(28.6 \%)$ falling in Rajasthan and the populated central (-58.4\%) and eastern regions (-15.3\%). A similar spatial dichotomy in anomalies was also found during Phase 3 with urban Delhi showing a $45.6 \%$ decline while rural areas showing a 36.5\% increase. High positive anomalies observed in the western desert region can be attributed to the small $\mathrm{NO}_{2}$ columns values wherein; slight changes in concentrations appear as large anomalies. Overall anomaly during Phase 3 was $-7.2 \% \pm 31.3 \%$. During Phase 4 , when most restrictions had been relaxed, $\mathrm{NO}_{2}$ density anomaly in Delhi reduced to $-37.7 \%$ from the $-76.8 \%$ during Phase 1. For the first time since the Phase 1 onset, concentration increased over the Panipat region, which has a power-plant and an oil refinery closely located to each other, showed a positive anomaly of $37.3 \%$. Furthermore, Phase 4 coincided with the large-scale open wheat crop-residue burning in the northern regions of the domain, resulting in positive $\mathrm{NO}_{2}$ anomalies. The overall anomaly for Phase 4 was $-4.5 \% \pm 15.4 \%$. During Phase 5, which saw no restrictions except in containment zones, density anomalies remained lower than that during BAU, suggesting that concentrations had still not recovered to the same levels as those in 2019 with overall anomaly as $17.5 \% \pm 12.3 \%$. Lower anomalies may also have been partly contributed by unusual precipitation that took place during the latter half of June $2020^{40}$. The eastern-western spatial dichotomy was not apparent during Phase 5. Interestingly, negative anomalies were persistent over most of the urban region of Delhi and downwind regions of strong emitters such as power plants and refineries during all the phases while fluctuating in other regions.

However, the reduction in concentration cannot be conclusively calculated without adjusting for long-term trends. Reductions in concentrations were further analyzed by calculating anomaly with respect to the expected concentration. Furthermore, spatial differences in anomaly in the western and eastern portion of the domain suggests possible varying influence of wind speeds and direction in dispersing away the pollutants. This confounding by wind was addressed by estimating the impact on emissions (Section 3.2).

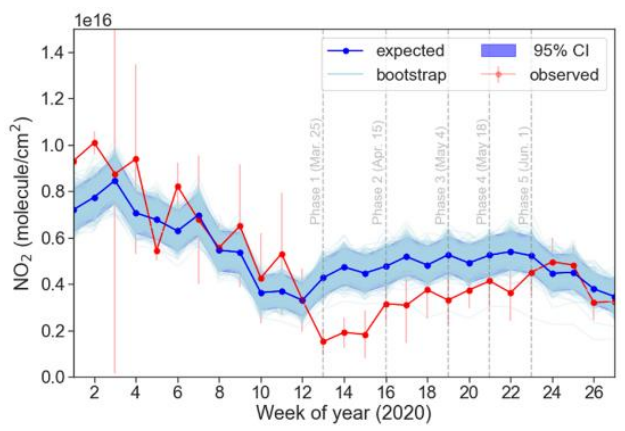

(a) Observed, expected $\mathrm{NO}_{2}$ over urban region

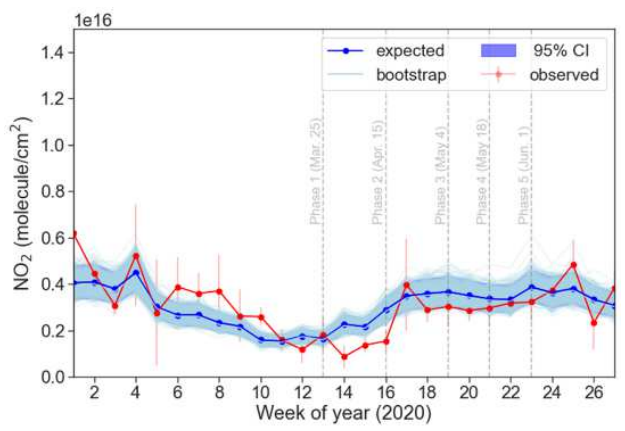

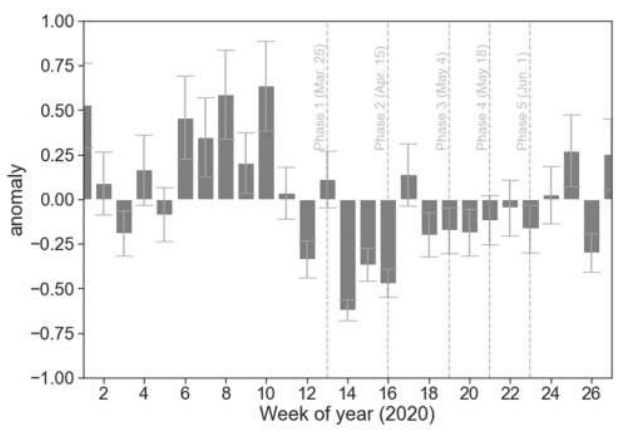

(b) $\mathrm{NO}_{2}$ anomaly over urban region

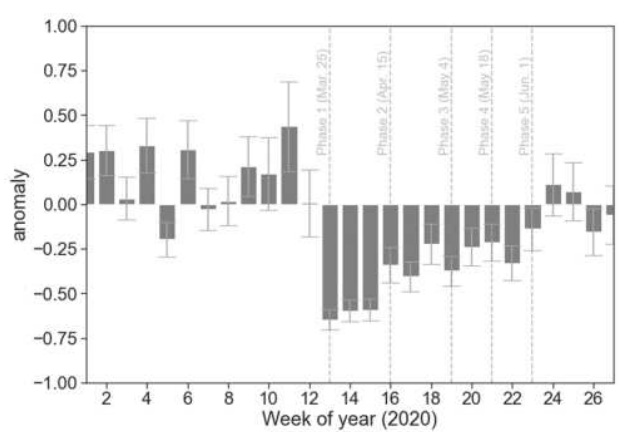


(c) Observed, expected $\mathrm{NO}_{2}$ over rural

(d) $\mathrm{NO}_{2}$ anomaly over rural region

region

Figure 2. Mean weekly observed and predicted $\mathrm{NO}_{2}$ columns (left) and their anomaly between the observed and predicted columns (right) for Delhi (top) and rural Fatehabad (bottom). The anomaly range corresponds to $95 \%$ prediction intervals. Anomaly metric was calculated following Equation 1 .

Figure 2 shows the retrieved $\mathrm{OMI} \mathrm{NO} 2$ column as well as the expected $\mathrm{OMI} \mathrm{NO}_{2}$ column over urban and the rural location and their corresponding anomalies for both the locations. Based on the STL decomposition, a small but significantly decreasing $\mathrm{NO}_{2}$ linear trend from 2016 to 2019 was found over the urban Delhi $\left(-0.142 \times 10^{15} \mathrm{yr}^{-1}\right)$ as well as rural Fatehabad area. Seasonality of $\mathrm{NO}_{2}$ after STL decomposition shows a high $\mathrm{NO}_{2}$ in the winter months (January and February) over Delhi and Fatehabad that gradually decreases with pre-monsoon summer. The seasonality corresponding to the photolysis rate, life-time and change in emissions. The photolysis rate of $\mathrm{NO}_{2}$ is proportionally related with actinic flux, which increases with decreasing solar zenith angle (as well as depending on direct, diffused and reflected radiation governed by amount and type of the aerosols, absorbing gases, air molecules and the surface albedo ${ }^{18}$. A lower actinic flux during winter results in a lower $\mathrm{NO}_{2}$ photolysis frequency and $\mathrm{OH}$ radical production rate, thereby reducing the photochemical loss of $\mathrm{NO}_{2}$ and increasing its lifetime ${ }^{32}$. As the pre-monsoon dry summer with its high temperature starts approaching, actinic flux increases, thereby decreasing the lifetime of $\mathrm{NOx}$ and lowering $\mathrm{NO}_{2}$ column densities. Further with onset of monsoon, wet deposition reduces the $\mathrm{NO}_{2}$. As seen in Figure 2 (a) and (c), observed and expected $\mathrm{NO}_{2}$ column densities during the BAU phase were similar, as evidenced by their small mean $\mathrm{NO}_{2}$ anomalies existing over Delhi (15.7\%) and Fatehabad (20.3\%) respectively. However, when the lockdown commenced, urban $\mathrm{NO}_{2}$ showed a sharp deviation from the expected densities. During the Phase 1 of lockdown, similar $\mathrm{NO}_{2}$ column values were observed in urban Delhi and rural Fatehabad (Figure 2 (a) and (c)). The greatest negative anomaly over Delhi was observed during the first week of the Phase 1 as $-64.51 \%$ (-56.9\% to $-70.2 \%)$. However, for the rural Fatehabad a positive anomaly was observed during the first week of Phase 1 as $11.2 \%(-4.7 \%$ to $31.8 \%$ ) which during the second week of Phase 1 dipped to $-62.1 \%$ (-68.0\% to $-54.3 \%)$.

By comparing mean anomalies across lockdown phase and locations (Table 1), it becomes clear that urban Delhi showed larger anomalies than rural Fatehabad and its reduced concentrations persisted for a longer duration than Fatehabad. Mean anomalies during Phase 2 to Phase 4 in Delhi stayed between $-31 \%$ to $-27 \%$, suggesting slight recovery in emissions compared to Phase 1 reductions. During the same duration Fatehabad had lower mean anomalies between $-8 \%$ to $-15 \%$ suggesting that impact of the policy restrictions on human activity and consequently $\mathrm{NO}_{2}$ was not uniform in urban and rural areas. In urban areas, industrial and transportation activities did not resume to pre-COVID levels even during the unlock Phase 5 resulting in overall negative anomalies. However, in rural areas consistent smaller anomalies could be related to their permission to conduct agricultural activities (such as harvesting and transport) as usual as the inclusion of agricultural activities within 'essential services' excluded them from lockdown restrictions. Another reason could be that contribution of anthropogenic emissions from rural household biomass fuel burning as well as biogenic emission from agricultural soil ${ }^{18}$ kept on contributing to rural $\mathrm{NO}_{2}$ columns despite the lockdown. Sporadic thunderstorms reported in the region between March and May have increased tropospheric $\mathrm{NO}_{2}$ as lightning can contribute up to $0.4 \times 10^{15}$ molecules $\mathrm{cm}^{-2}$ in tropical continents ${ }^{41}$.

Table 1. Mean phase-wise anomaly between the observed and predicted $\mathrm{NO}_{2}$ concentrations in 2020. The range corresponds to $95 \%$ prediction intervals.

\begin{tabular}{lll} 
Phase & Urban (Delhi) & Rural (Fatehabad) \\
\hline BAU & $15.7 \%(0.0 \%$ to $36.3 \%)$ & $20.3 \%(5.6 \%$ to $44.0 \%)$ \\
Phase 1 & $-61.0 \%(-67.0 \%$ to $-53.0 \%)$ & $-33.5 \%(-43.3 \%$ to $20.7 \%)$ \\
Phase 2 & $-31.1 \%(-42.0 \%$ to $-19.3 \%)$ & $-7.7 \%(-22.0 \%$ to $10.8 \%)$
\end{tabular}




$\begin{array}{lll}\text { Phase } 3 & -30.4 \%(-40.0 \% \text { to }-17.4 \%) & -15.0 \%(-28.6 \% \text { to } 1.8 \%) \\ \text { Phase } 4 & -27.0 \%(-37.0 \% \text { to }-13.4 \%) & -10.5 \%(-25.0 \% \text { to } 6.6 \%) \\ \text { Phase } 5 & -3.4 \%(-18.4 \% \text { to } 16.2 \%) & 6.2 \%(10.4 \% \text { to } 27.3 \%)\end{array}$

\subsection{NOx emission change during lockdown}

Top-down emissions change during each phase in Figure 3 depicts a more accurate policy impact on $\mathrm{NO}_{2}$ compared to change in concentrations by overcoming the effect of wind on plume advection. Compared to BAU, substantial emission reduction was observed over urban Delhi as well as surrounding areas. As investigated earlier ${ }^{42-44}$ (also discussed in supplementary file), NOx emission in Delhi is mostly contributed by traffic and industries, amounting to $58 \%$ to $80 \%$ of total emissions. Apart from the urban areas, emissions from Harduaganj and Dadri power-plant as well as the oil refinery in Panipat were reduced substantially. Emission rates were similar in Phase 1, 2 and 3. During Phase 4, when most restrictions had been removed, emissions increased in areas within and surrounding Delhi as well as at the Panipat oil refinery. Such resumption in oil refining activities was also been reported in newspapers ${ }^{45}$. Also, several scattered weakly emitting point sources in northern Haryana, possibly corresponding to crop residue fires are visible. During the unlock Phase 5, emissions remained mostly similar to Phase 4, except at Panipat oil refinery where they had decreased compared to Phase 4 but higher than Phase 1.

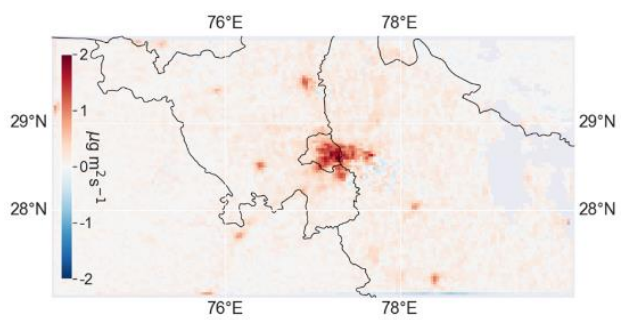

(a) BAU

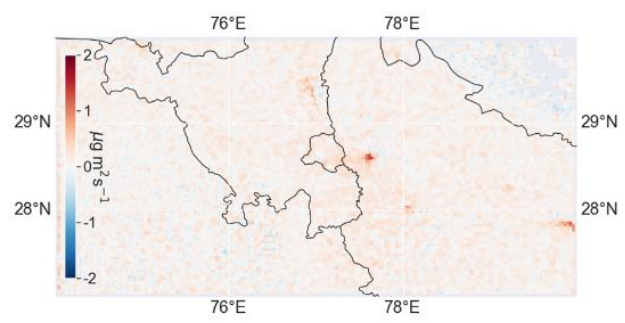

(c) Phase 2

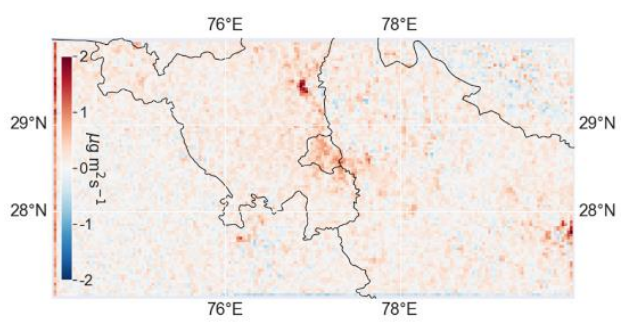

(e) Phase 4

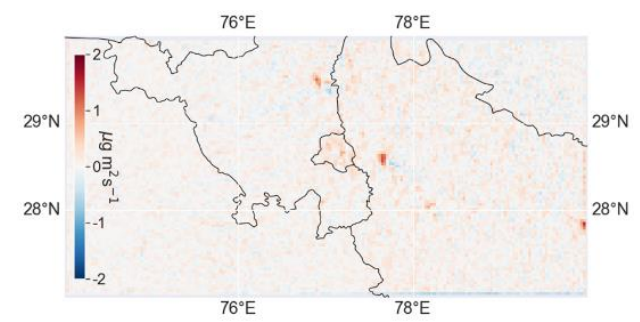

(b) Phase 1

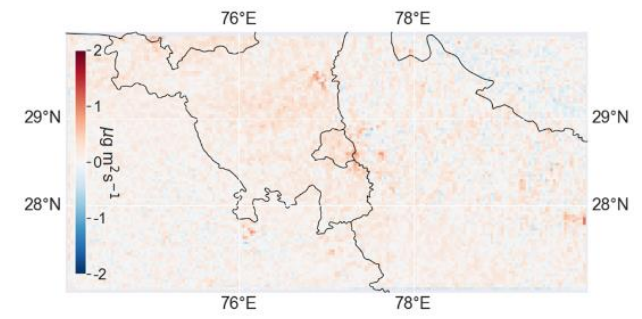

(d) Phase 3

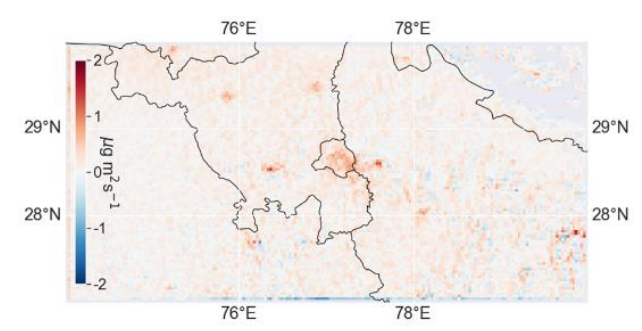

(f) Phase 5

Figure 3. Phase-wise mean top-down NOx emission in 2020 during (a) BAU (business-as-usual), and subsequent lockdown phases (b)-(f).

A time-series comparison of top-down emission with activity reports for Delhi (Dadri powerplant and Harduaganj power-plant) is shown in Figure 4 (Figure S4). Interestingly, weekly emission from urban areas showed a slight decreasing trend between January and prior to lockdown in March. It is possible that relatively higher emission estimation in January was due to biomass burning for 
heating. It is also possible that emission is slightly underestimated in March due to the assumption of a higher than actual $\tau$, which may be unlikely due to an increased photolysis rate during March. Over these three locations (urban Delhi, Harduaganj power-plant and Dadri power-plant), correlation between the reported activity and top-down emission is higher than the correlation between the activity and concentration (Table S2). This confirms that changes in top-down emissions assess the lockdown impacts better than the concentration since the emission overcome confounding from wind-field related meteorological effects. However for power-plants, a small difference between activity-concentration correlation and the activity-emission correlation suggests that over strong point sources lockdown impacts can be equally informed by changes in either emissions or concentrations. A high correlation between the emission and the mobility activity over the urban area (0.96) re-confirms that most NO2 emissions are related with people's movement activities from transportation as was also suggested in previous bottom-up emission inventories studies.

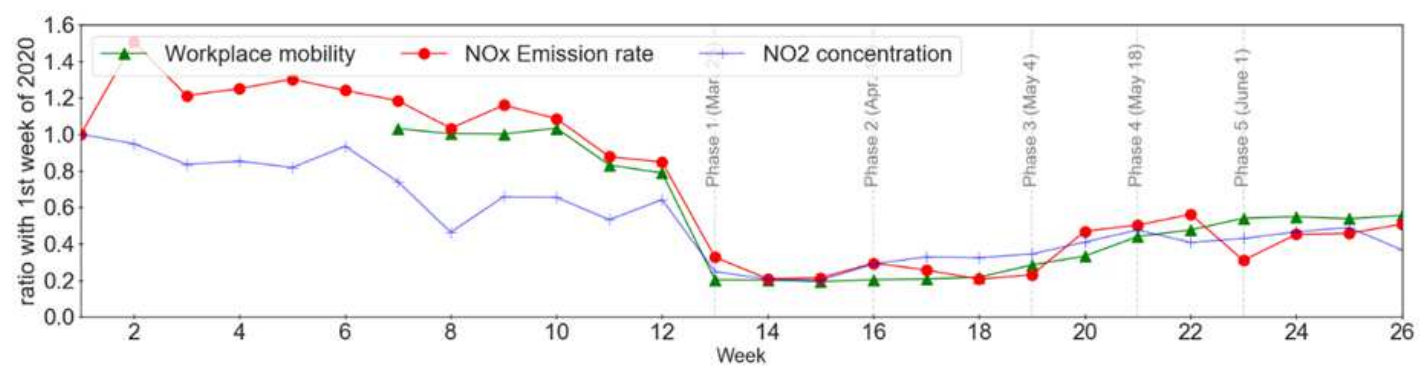

Figure 4. Mean relative activity, $\mathrm{NOx}$ emission and $\mathrm{NO}_{2}$ concentration standardized with respect to mean values in the first week of January 2020 (6 January - 12 January, 2020) at Delhi

Emission anomalies were calculated by comparing the emission during lockdown phases with the mean emission in the three weeks prior to the lockdown. Emission during Phase 1 decreased by $72.19 \%$ over the urban area which by Phase 5 had recovered to $49.5 \%$ decrease. At the same time, compared to the baseline, workplace mobility had decreased by average $80.6 \%$ in the initial Phase 1 and by $45.5 \%$ in Phase 5. At the Harduaganj and Dadri power-plants, lower demands led to a power production decrease by $20 \%$ and $55 \%$ respectively. At the corresponding locations mean emission decreased by $53.4 \%$ and $48.5 \%$ during Phase 1 and Phase 2 compared to BAU.

Emission anomalies in 2020 were also calculated with respect to the corresponding emissions of 2019 as reference. Emissions anomalies so calculated are visualized spatially for each phase in Figure S3 and summarized for Delhi in Table 2. As transportation and factories came to standstill during the Phase1, for Delhi about 72\% NOx emissions can be attributed solely to the traffic and factories.

Table 2. Mean top-down NOx emission ( \pm standard deviation) in 2020 and its anomaly with respect to 2019 emissions over a $60 \times 60 \mathrm{~km} 2$ region around central Delhi $(77.21 \mathrm{E}, 28.60 \mathrm{~N})$.

\begin{tabular}{lll} 
Phase & mean emission $(\mathrm{kg} / \mathrm{sec})$ & anomaly compared to 2019 \\
\hline BAU & $2.78 \pm 0.43$ & $-17.3 \%$ \\
Phase 1 & $0.61 \pm 0.13$ & $-72.0 \%$ \\
Phase 2 & $0.62 \pm 0.09$ & $-63.2 \%$ \\
Phase 3 & $0.85 \pm 0.29$ & $-50.3 \%$ \\
Phase 4 & $1.30 \pm 0.72$ & $-29.4 \%$ \\
Phase 5 & $1.05 \pm 0.18$ & $-40.6 \%$
\end{tabular}

\subsection{Uncertainty in satellite retrieved tropospheric $\mathrm{NO}_{2}$ and top-down $\mathrm{NOx}$ emissions}

Tropospheric $\mathrm{NO}_{2}$ retrievals can suffer uncertainty in slant column density (due to measurement noise and spectral fitting errors), stratospheric slant column (due to error in separating stratospheric and tropospheric $\mathrm{NO}_{2}$ ) and tropospheric AMF (due to model parameter errors such as assumed 
uncertainty due to AMF is about $30 \%$. If the satellite retrieval assumed $\mathrm{NO}_{2}$ height profile has a smaller aerosol fraction close to surface compared to the true profile, then tropospheric AMF will be overestimated and correspondingly the retrieved tropospheric $\mathrm{NO}_{2} \mathrm{VCD}$ will be underestimated 7 . Shaiganfar et al., (2011) compared OMI NO 2 VCD with MAX-DOAS observations and found that OMI underestimates high values over Delhi. Over highly polluted regions tropospheric $\mathrm{NO}_{2} \mathrm{VCDs}$ are partially underestimated due to shielding of emitted $\mathrm{NO}_{2}$ by aerosols ${ }^{1}$. The random errors are reduced by temporal and spatial averaging, while a major part of systematic errors is expected to cancel out through the difference and ratio in the defined anomaly metric.

Estimation of total emission is complicated mainly by variation of wind field and chemical transformation ${ }^{2,8}$. As long as wind has a constant speed and direction and these parameters are known with low uncertainty. However slow winds which change directions with time and space complicate emission estimation as such scenarios have high uncertainty (relative to wind speed) and the sudden change in wind direction breaks the steady-state assumption. However, the error due to non-stationary state is smaller near point sources and that further diminishes by a multi-temporal mean. Another problem is that while the wind speeds and directions change with altitude, the vertical profile of the trace gas itself is not well-known. For example, the near-surface emissions (from vehicles) and chimney-stack emissions are injected at different altitude and their dispersion is subjected to different wind speeds. Chemical reactions may also add uncertainties in the assumed lifetime and the constant Leighton ratio. As stated earlier $\mathrm{NO}_{2} / \mathrm{NOx}$ ratio is lower when close to the freshly emitting source in space and time, which increases in aged plumes after chemical conversion?. Near strong emission sources emitted $\mathrm{NO}$ may not be quickly converted to $\mathrm{NO}_{2}$ if the $\mathrm{NO}$ mixing ratios locally exceed those of $\mathrm{O} 3$. The $\mathrm{NO} / \mathrm{NO}_{2}$ steady state will be completely achieved only after ambient air has mixed with the emitted plume ${ }^{1}$. Turbulence in wind speed, may enhance mixing and conversion of $\mathrm{NO}$ to $\mathrm{NO}_{2}$ near the source or it may disperse $\mathrm{NO}$ to downwind before it gets converted to $\mathrm{NO}_{2}{ }^{9}$. We assumed a constant ratio of $\mathrm{NO} / \mathrm{NO}_{2}$, neglecting possible changes by day of the week. We also assumed that chemical loss of NOx is first-order given by a constant lifetime $\tau$ and neglecting possible change in $\tau$ due to seasonality in actinic flux, different ozone concentrations on weekends ${ }^{10}$ or during the lockdown ${ }^{11}$ and dilution by wind.

\section{Conclusions}

The natural experiment induced by COVID-19 lockdown was used to assess the impact of lockdown on NOx concentration and anthropogenic emissions in a region in Northern India around Delhi. To estimate the decline in $\mathrm{NO}_{2}$ during the lockdown, seasonality and trend decomposition was used to calculate the expected $\mathrm{NO}_{2}$ in 2020 by extrapolating it from previous years. Compared to the expected concentrations, $\mathrm{NO}_{2}$ concentration in urban areas reduced by $60 \%$ in Phase 1 of lockdown to $3 \%$ in Phase 5 of lockdown. In contrast, the rural areas exhibited much smaller and short-lived reductions suggesting a lower impact of the movement restriction policies. To estimate the detailed impact of the lockdown top-down emissions were estimated spatially using steady state continuity equation by considering the transport of pollutants. The calculations suggest compared to the business-as-usual phase of 2020, emission over the urban area and power-plants decreased by $72.19 \%$ and $53.4 \%$, respectively during the Phase 1 of lockdown. By Phase 5, emissions over urban areas had recovered, showing a decrease of $49.5 \%$ compared to business-as-usual phase of 2020 . Higher correlation of activity reports with emission compared to concentrations, suggested that top-down emissions are representative for estimating the impact of lockdown specially over urban areas. This analysis can be extended to link the varying impacts of diverse policy regulations on emission sources and consequently on NOx emissions

\section{References}

1. Bonaccorsi, G. et al. Economic and social consequences of human mobility restrictions under COVID-19. Proc. Natl. Acad. Sci. U. S. A. 117, 15530-15535 (2020).

2. McKibbin, W. \& Fernando, R. The Global Macroeconomic Impacts of COVID-19: Seven Scenarios. Asian 
Econ. Pap. 1-55 (2020). doi:10.1162/asep_a_00796

3. Dhaka, S. K. et al. $\operatorname{PM(2.5)~diminution~and~haze~events~over~Delhi~during~the~COVID-19~lockdown~}$ period: an interplay between the baseline pollution and meteorology. Sci. Rep. 10, 13442 (2020).

4. Diamond, M. S. \& Wood, R. Limited Regional Aerosol and Cloud Microphysical Changes Despite Unprecedented Decline in Nitrogen Oxide Pollution During the February 2020 COVID-19 Shutdown in China. Geophys. Res. Lett. 47, (2020).

5. Chauhan, A. \& Singh, R. P. Decline in PM2.5 concentrations over major cities around the world associated with COVID-19. Environ. Res. 187, 109634 (2020).

6. Le, T. et al. Unexpected air pollution with marked emission reductions during the COVID-19 outbreak in China. Science (80-. ). 369, 702-706 (2020).

7. Zhao, Y. et al. [ASAP] Substantial Changes in Nitrate Oxide and Ozone after Excluding Meteorological Impacts during the COVID-19 Outbreak in Mainland China. Environ. Sci. Technol. Lett. acs.estlett.0c00304 (2020). doi:10.1021/acs.estlett.0c00304

8. Shi, X. \& Brasseur, G. P. The Response in Air Quality to the Reduction of Chinese Economic Activities During the COVID-19 Outbreak. Geophys. Res. Lett. 47, (2020).

9. Bauwens, M. et al. Impact of Coronavirus Outbreak on NO2 Pollution Assessed Using TROPOMI and OMI Observations. Geophys. Res. Lett. 47, (2020).

10. Chen, R. et al. Associations between short-term exposure to nitrogen dioxide and mortality in 17 Chinese cities: The China Air Pollution and Health Effects Study (CAPES). Environ. Int. 45, 32-38 (2012).

11. Kotnala, G., Mandal, T. K., Sharma, S. K. \& Kotnala, R. K. Emergence of Blue Sky Over Delhi Due to Coronavirus Disease (COVID-19) Lockdown Implications. Aerosol Sci. Eng. 4, 228-238 (2020).

12. Mahato, S., Pal, S. \& Ghosh, K. G. Effect of lockdown amid COVID-19 pandemic on air quality of the megacity Delhi, India. Sci. Total Environ. 730, 139086 (2020).

13. Singh, V. et al. Diurnal and temporal changes in air pollution during COVID-19 strict lockdown over different regions of India. Environ. Pollut. 266, 115368 (2020).

14. Singh, R. P. \& Chauhan, A. Impact of lockdown on air quality in India during COVID-19 pandemic. Air Quality, Atmosphere and Health 13, 921-928 (2020).

15. Kumar, P. et al. Temporary reduction in fine particulate matter due to 'anthropogenic emissions switchoff' during COVID-19 lockdown in Indian cities. Sustain. Cities Soc. 62, 102382 (2020).

16. Sharma, S. et al. Effect of restricted emissions during COVID-19 on air quality in India. Sci. Total Environ. 728, 138878 (2020).

17. Vlemmix, T. et al. MAX-DOAS tropospheric nitrogen dioxide column measurements compared with the Lotos-Euros air quality model. Atmospheric Chemistry and Physics 15, 1313-1330 (2015).

18. Ghude, S. D., Fadnavis, S., Beig, G., Polade, S. D. \& van der A, R. J. Detection of surface emission hot spots, trends, and seasonal cycle from satellite-retrieved NO2 over India. J. Geophys. Res. Atmos. 113, 113 (2008).

19. Ghude, S. D. et al. Application of satellite observations for identifying regions of dominant sources of nitrogen oxides over the indian subcontinent. J. Geophys. Res. Atmos. 118, 1075-1089 (2013).

20. Ding, J. et al. NOx Emissions Reduction and Rebound in China Due to the COVID-19 Crisis. Geophys. Res. Lett. 47, (2020).

21. Miyazaki, K. et al. Air Quality Response in China Linked to the 2019 Novel Coronavirus (COVID-19) Lockdown. Geophys. Res. Lett. 47, (2020).

22. Zhang, R. et al. NOx emission reduction and recovery during COVID-19 in East China. Atmosphere 
(Basel). 11, 433 (2020).

23. Levelt, P. F. et al. The ozone monitoring instrument. IEEE Trans. Geosci. Remote Sens. (2006). doi:10.1109/TGRS.2006.872333

24. Griffin, D. et al. High-Resolution Mapping of Nitrogen Dioxide With TROPOMI: First Results and Validation Over the Canadian Oil Sands. Geophys. Res. Lett. 46, 1049-1060 (2019).

25. Acker, J., Soebiyanto, R., Kiang, R. \& Kempler, S. Use of the NASA giovanni data system for geospatial public health research: Example of weather-influenza connection. ISPRS Int. J. Geo-Information (2014). doi:10.3390/ijgi3041372

26. Gorelick, N. et al. Google Earth Engine: Planetary-scale geospatial analysis for everyone. Remote Sens. Environ. 202, 18-27 (2017).

27. Boersma, K. F. et al. An improved tropospheric NO2 column retrieval algorithm for the Ozone Monitoring Instrument. Atmos. Meas. Tech. 4, 1905-1928 (2011).

28. NCEP. National Centers for Environmental Prediction/National Weather Service/NOAA/U.S. Department of Commerce. 2000, updated daily. NCEP FNL Operational Model Global Tropospheric Analyses, continuing from July 1999 (2000). doi:10.5065/D6M043C6

29. Le Quéré, C. et al. Temporary reduction in daily global CO2 emissions during the COVID-19 forced confinement. Nat. Clim. Chang. 1-7 (2020). doi:10.1038/s41558-020-0797-x

30. POSOCO. Daily Regional Power Supply Position. Available at: https://nrldc.in/reports/dailyreports/daily-regional-power-supply-position/. (Accessed: 21st May 2020)

31. Google. COVID-19 Community Mobility Reports. Available at: https://www.google.com/covid19/mobility/. (Accessed: 21st May 2020)

32. Beirle, S., Platt, U., Wenig, M. \& Wagner, T. Weekly cycle of NO2 by GOME measurements: A signature of anthropogenic sources. Atmospheric Chemistry and Physics 3, 2225-2232 (2003).

33. Martin, R. V. Global inventory of nitrogen oxide emissions constrained by space-based observations of NO 2 columns. J. Geophys. Res. 108, 4537 (2003).

34. Shaiganfar, R. et al. Estimation of $\mathrm{NO} x$ emissions from Delhi using Car MAX-DOAS observations and comparison with OMI satellite data. Atmos. Chem. Phys. 11, 10871-10887 (2011).

35. Lorente, A. et al. Quantification of nitrogen oxides emissions from build-up of pollution over Paris with TROPOMI. Sci. Rep. 9, 20033 (2019).

36. Beirle, S. et al. Pinpointing nitrogen oxide emissions from space. Sci. Adv. 5, 1-7 (2019).

37. Seinfeld, J. H. Urban Air Pollution : State of the Science. Science (80-. ). (1989).

38. Kimbrough, S., Chris Owen, R., Snyder, M. \& Richmond-Bryant, J. NO to NO2 conversion rate analysis and implications for dispersion model chemistry methods using Las Vegas, Nevada near-road field measurements. Atmospheric Environment 165, 23-34 (2017).

39. Beirle, S., Boersma, K. F., Platt, U., Lawrence, M. G. \& Wagner, T. Megacity emissions and lifetimes of nitrogen oxides probed from space. Science (80-. ). 333, 1737-1739 (2011).

40. New Delhi, India Weather History | Weather Underground. Available at: https://www.wunderground.com/history/monthly/in/new-delhi/VIDD/date/2020-6. (Accessed: 18th September 2020)

41. Boersma, K. F., Eskes, H. J., Meijer, E. W. \& Kelder, H. M. Estimates of lightning NO2 production from GOME satellite observations. Atmospheric Chemistry and Physics Discussions 5, 3047-3104 (2005).

42. Sahu, S. K. High Resolution Emission Inventory of NOx and CO for Mega City Delhi, India. Aerosol Air Qual. Res. 2015, 1137-1144 (2015). 
43. Sindhwani, R., Goyal, P., Kumar, S. \& Kumar, A. Anthropogenic emission inventory of criteria air pollutants of an urban agglomeration - National capital region (NCR), Delhi. Aerosol Air Qual. Res. 15, 1681-1697 (2015).

44. Guttikunda, S. K. \& Calori, G. A GIS based emissions inventory at $1 \mathrm{~km} \times 1 \mathrm{~km}$ spatial resolution for air pollution analysis in Delhi, India. Atmos. Environ. 67, 101-111 (2013).

45. Indian Oil's refineries to operate at $80 \%$ capacity. The Hindu (2020). Available at: https://www.thehindu.com/business/indian-oils-refineries-to-operate-at-80capacity/article31560534.ece. (Accessed: 17th September 2020)

Acknowledgments: This research is financially supported by Research Institute for Humanity and Nature (RIHN: a constituent member of NIHU) Project No. 14200133 (Aakash).

Author Contributions: Conceptualization, P.M., P.K.P. and S.H.; Data curation, P.M., M.T., S.K.D., K.Y. and P.K.P.; Formal analysis, P.M.; Funding acquisition, S.H.; Investigation, P.K.P., K.Y., M.K., W.T., R.I. ; Methodology, P.M., P.K.P. and S.H.; Project administration, P.K.P. and S.H.; Resources, M.T., P.K.P. and S.H; Software, P.M.; Validation, P.M., K.Y., M.K., S.K.D., A.P.D.; Visualization, P.M., W.T., P.K.P., S.H. ; Writingoriginal draft, P.M.; Writing-review \& editing, P.M., P.K., S.K.D., A.P.D., and S.H.

Conflicts of Interest: The authors declare no conflict of interest. The funders had no role in the design of the study; in the collection, analyses, or interpretation of data; in the writing of the manuscript, or in the decision to publish the results.

Data availability: Publicly available datasets were. TROPOMI was processed and downloaded from Google Earth Engine, OMI was downloaded from NASA's Giovanni platform and meteorological data obtained from NCAR's Research Data Archive. Original code was developed by the authors for top-down emission estimation 


\section{Figures}
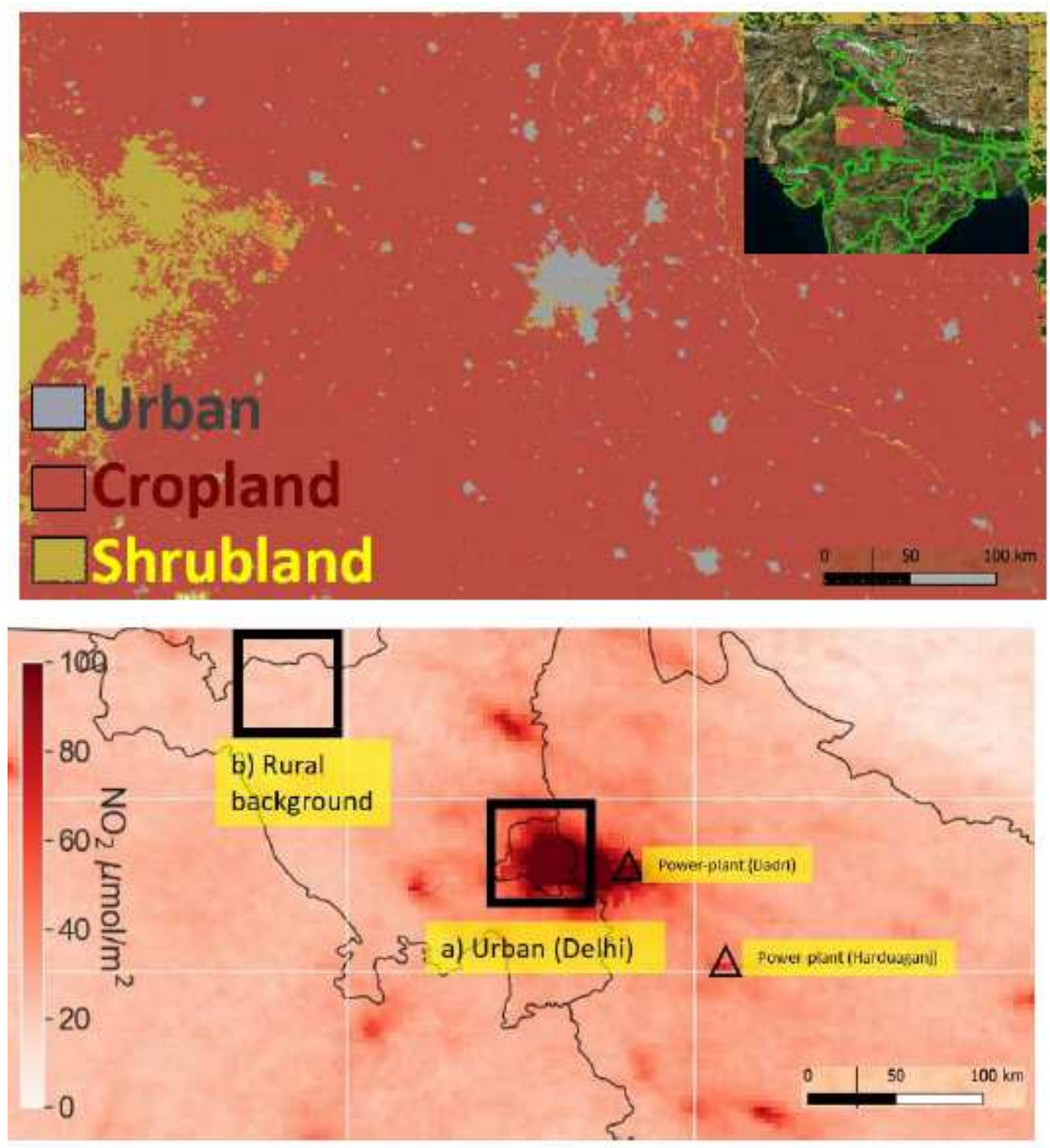

\section{Figure 1}

(top) Dominant land cover types in the study domain $\left(74^{\circ} \mathrm{E}, 27^{\circ} \mathrm{N}-80^{\circ} \mathrm{E}, 30^{\circ} \mathrm{N}\right)$ are urban areas, croplands and desert shrublands. (bottom) Mean NO2 column density (TROPOMI) in the week before the enactment of Phase 1 of lockdown March 16-20 (week 12), 2020. Location of representative urban area (Delhi) and rural background (Fatehabad) are shown in box, in addition to other prominent neighboring emission sources (power-plant at Dadri and Harduaganj). Note: The designations employed and the presentation of the material on this map do not imply the expression of any opinion whatsoever on the part of Research Square concerning the legal status of any country, territory, city or area or of its authorities, or concerning the delimitation of its frontiers or boundaries. This map has been provided by the authors. 


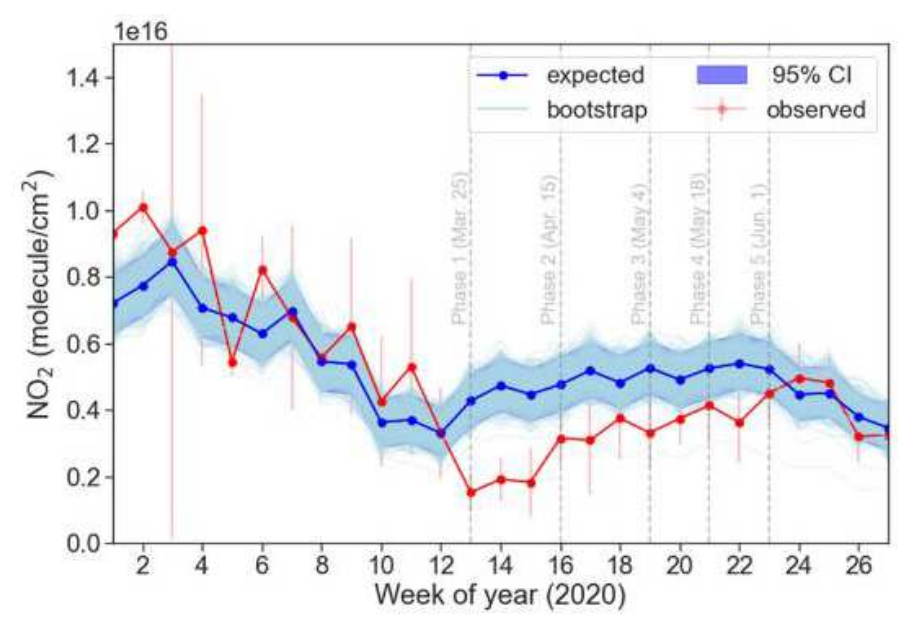

(a) Observed, expected $\mathrm{NO}_{2}$ over urban region

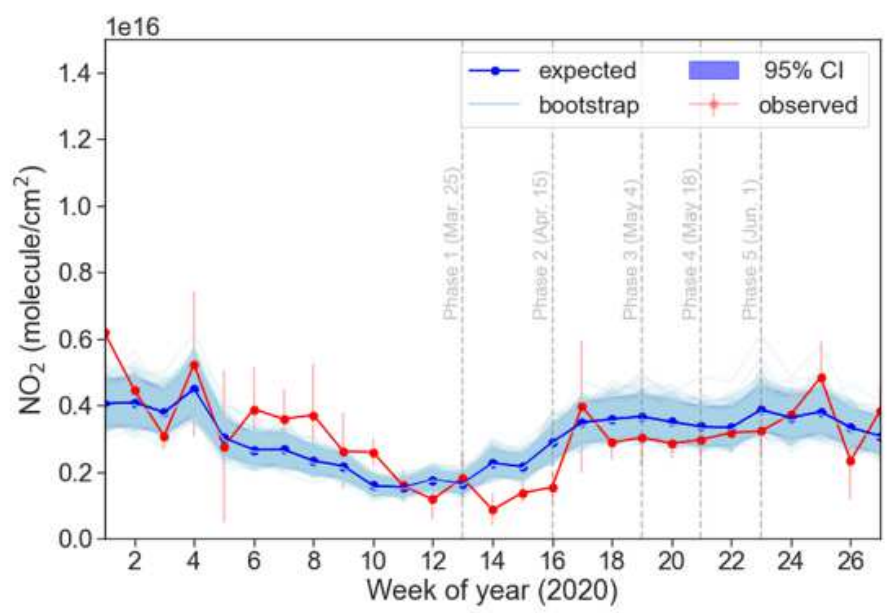

(c) Observed, expected $\mathrm{NO}_{2}$ over rural region

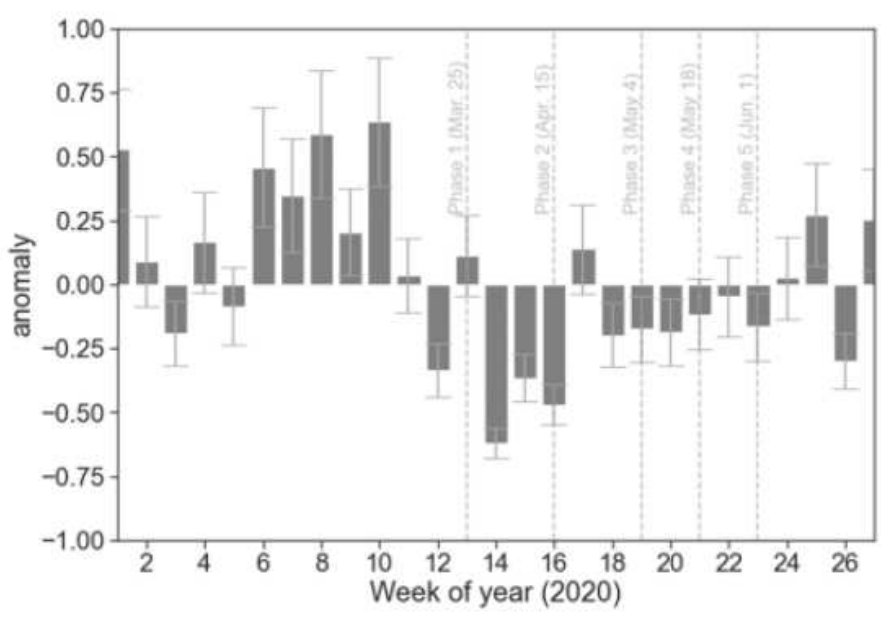

(b) $\mathrm{NO}_{2}$ anomaly over urban region



(d) $\mathrm{NO}_{2}$ anomaly over rural region

Figure 2

Mean weekly observed and predicted NO2 columns (left) and their anomaly between the observed and predicted columns (right) for Delhi (top) and rural Fatehabad (bottom). The anomaly range corresponds to $95 \%$ prediction intervals. Anomaly metric was calculated following Equation 1. 


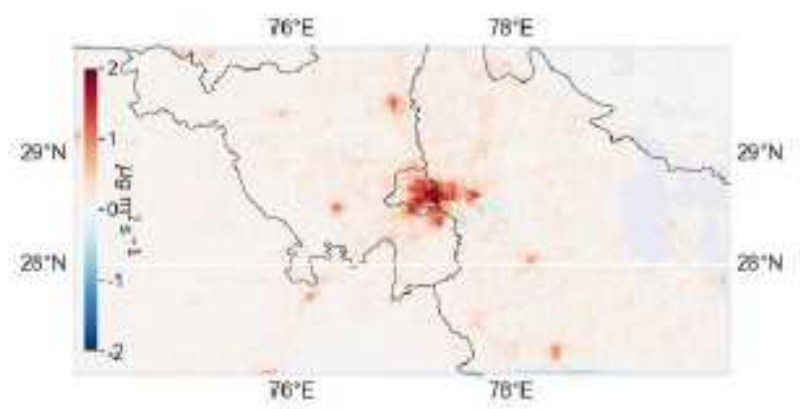

(a) BAU

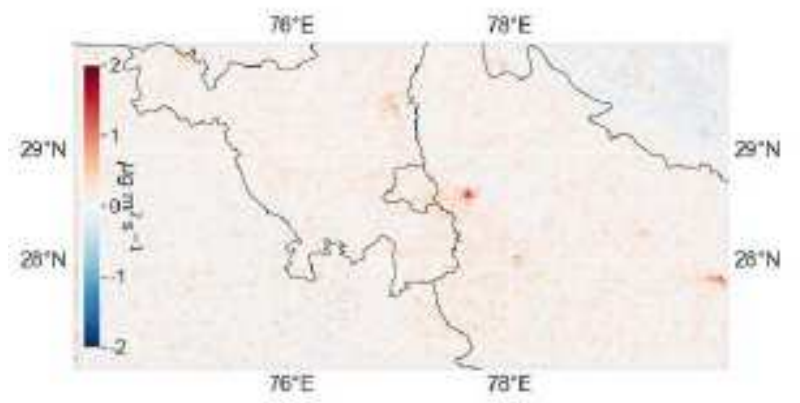

(c) Phase 2

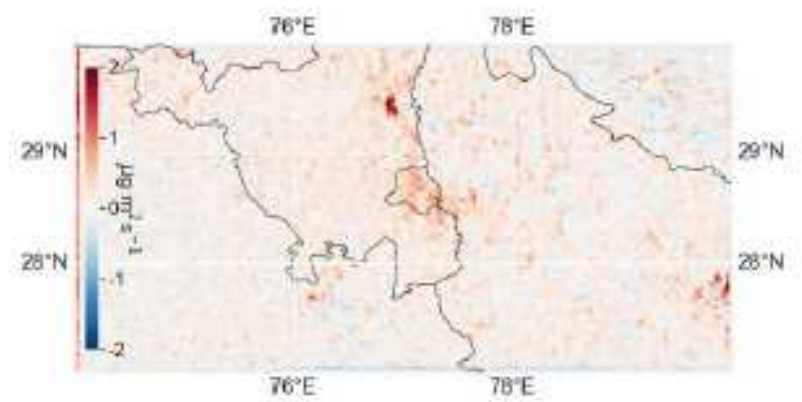

(e) Phase 4

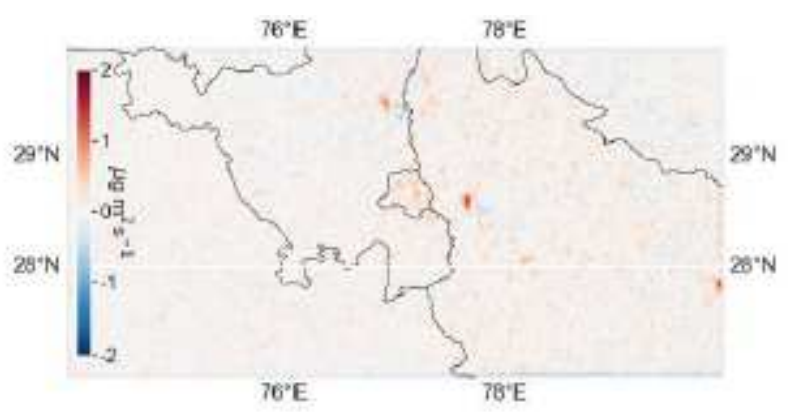

(b) Phase 1

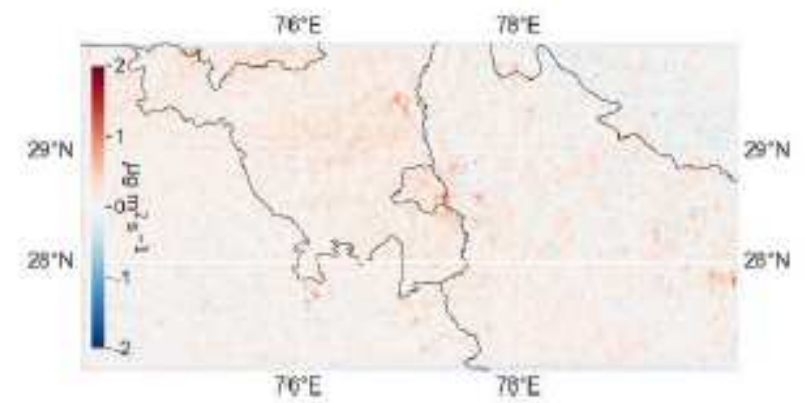

(d) Phase 3

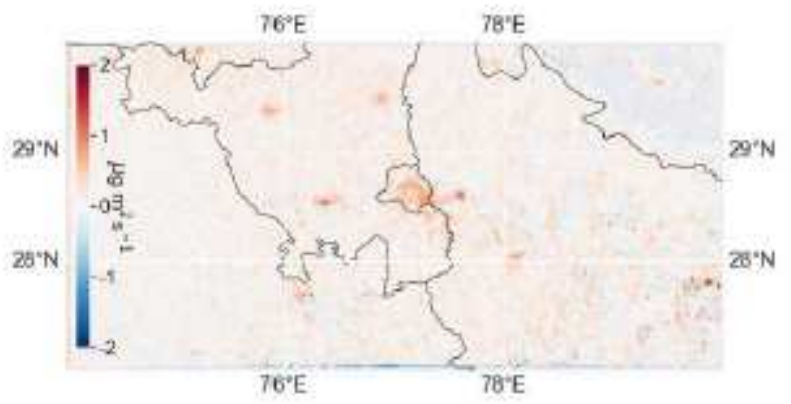

(f) Phase 5

Figure 3

Phase-wise mean top-down NOx emission in 2020 during (a) BAU (business-as-usual), and subsequent lockdown phases (b)-(f).

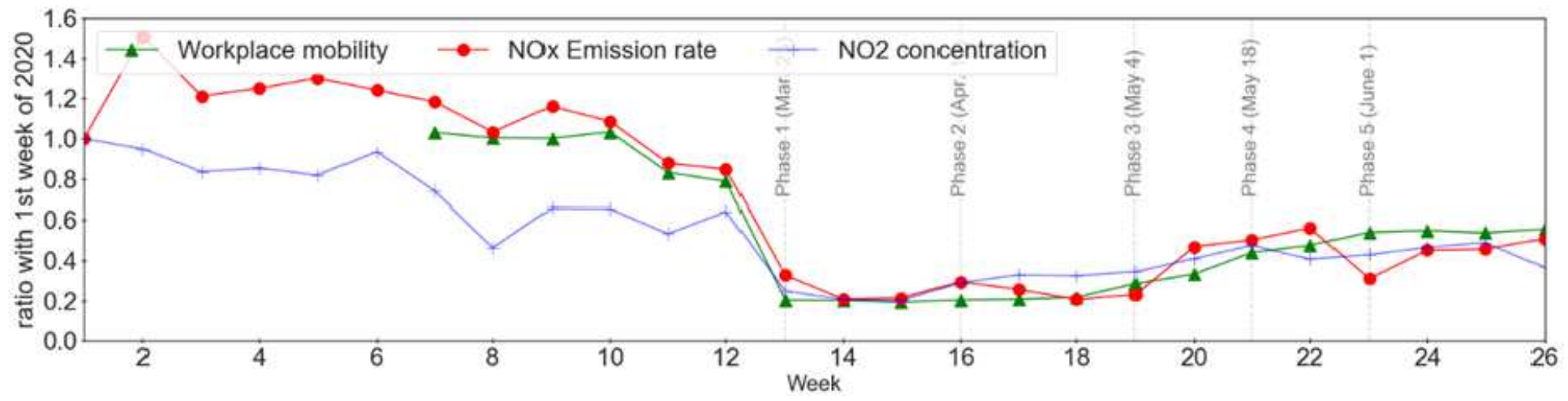

Figure 4 
Mean relative activity, NOx emission and NO2 concentration standardized with respect to mean values in the first week of January 2020 (6 January - 12 January, 2020) at Delhi

\section{Supplementary Files}

This is a list of supplementary files associated with this preprint. Click to download.

- 20201125NO2DELHISSupplementaryPM.pdf 